\title{
Crise do capital e o desmonte da Previdência Social no Brasil
}

\section{Crisis of the capital and dismantling of Social Security in Brasil}

\author{
Edvânia Ângela de Souza Lourenço \\ Pós-doutoranda em Saúde Coletiva, PPGSC da Unifesp. Membro do grupo de estudos: "Teoria Social de Marx e \\ Serviço Social", Unesp-Franca, SP, Brasil, coordenadora de graduação da Abepss-Sul II, 2017-2018.
}

edvaniaangela@hotmail.com

\section{Francisco Antonio de Castro Lacaz}

Professor titular da Universidade Federal de São Paulo, Escola Paulista de Medicina, São Paulo, SP, Brasil.

f.lacaz@unifesp.br

\begin{abstract}
Patrícia Martins Goulart
Doutora em Psicologia Social. Pós-doutoranda em Saúde Coletiva (PPGSC) da Universidade Federal de São Paulo, SP, Brasil.

pmg.correio@gmail.com
\end{abstract}

\begin{abstract}
Resumo: Discute-se a reforma em curso relativa ao desmonte da Previdência Social (PS) (PEC n. 287/2016), com atenção especial para a redução dos direitos dos trabalhadores, sob a justificativa do déficit da PS. Trata-se de um ensaio teórico, a partir de pesquisa bibliográfica e documental, cuja análise abarca as medidas "reformistas" também dos governos Fernando Henrique, Lula e Dilma. Observa-se que tais medidas evidenciam que, como uma real contrarreforma, regem-se pela lógica do setor privado, transformando direitos sociais em mercadorias com a redução drástica desses direitos.
\end{abstract}

Palavras-chave: Estado. Trabalho. Contrarreforma. Previdência Social.

\begin{abstract}
This article discusses the Social Security System (SSS) (PEC n. 287/2016), with particular attention to the reduction of workers' rights, under the justification of the SSS deficit. The analysis, based in legal documents and bibliography revision, includes the "reformists" measures adopted also by the Fernando Henrique, Lula, and Dilma governments in relation to SSS. It is concluded that the measures, like a real counter-reform are based on the logic of the private sector, and transforms social rights into goods and beckons for the drastic reduction of such rights.
\end{abstract}

Keywords: State. Work. Counter-reform. Social Security System. 


\section{Introdução}

$\mathrm{N}$

o Brasil, os direitos sociais foram reconhecidos tardiamente e são produtos da pressão operária e dos movimentos sociais, como ocorreu com a Constituição Federal (CF) de 1988, quando tais direitos foram frutos das lutas pela redemocratização do país. A Carta Constitucional ousou garantir o trabalho como direito social e a Previdência Social (PS) como parte do maior sistema de proteção social já implantado no país, configurando a Seguridade Social (SS), juntamente com a Assistência Social e a Saúde, num importante mecanismo para a efetivação do estado democrático de direito.

É verdade que os direitos previstos na CF de 1988 mal puderam revelar-se e logo foram obstaculizados pelo Executivo, a exemplo de como foi tratado o direito da pessoa com deficiência, a aposentadoria do idoso pobre, do trabalhador rural, entre outros. A justificativa era que os direitos sociais tornariam o Estado ingovernável, o que foi assumido no governo de José Sarney, ao não regulamentar o financiamento da SS, ao que se seguiu o ajuste fiscal de 1998, promovido por Fernando Henrique Cardoso (FHC), efetivando uma verdadeira contrarreforma do Estado de cunho neoliberal que atingiu a PS, a qual foi objeto da ação também dos governos de Luiz Inácio Lula da Silva e Dilma Rousseff.

No que tange à PS foi criado o Instituto Nacional de Seguro Social (INSS), ancorado no regime de repartição, com contribuições obrigatórias e que abrange trabalhadores da iniciativa privada, autônomos e algumas categorias especiais, os quais estão congregados no Regime Geral de Previdência Social (RGPS). Por outro lado, a partir de 1989, os funcionários públicos dos estados, municípios e União são cobertos pelo Regime Próprio de Previdência Social (RPPS), havendo, ainda, regime de previdência específico para os militares e Forças Armadas. Ademais, foi prevista a previdência privada por meio de regime complementar.

As mais importantes inovações no campo previdenciário materializadas na CF de 1988 podem ser resumidas em três grandes linhas: 1) introdução de um piso previdenciário a partir do valor do salário mínimo; 2) inclusão dos trabalhadores rurais (na qualidade de segurados especiais); 3) inclusão de idosos e de pessoas com deficiência, membros de famílias de baixa renda, constatada a renda per capita de até $1 / 4$ do salário mínimo, os quais passaram a receber o 
Benefício de Prestação Continuada (BPC), para o qual também foi garantido o piso de um salário mínimo (Marques e Mendes, 2004; Braga e Cabral, 2008).

Assim, alargou-se o conceito para além do seguro, o que permitiu que pessoas que não tinham contribuído para o sistema previdenciário pudessem contar com direitos, como é o caso da aposentadoria do trabalhador rural e do BPC gerido pela PS, porém fruto da regulamentação da Loas em 2003 (Brasil, 1993).

Essas conquistas, para ser efetivadas, necessitavam contar com fontes de receitas, sendo então criadas a Contribuição para o Financiamento da Seguridade Social (Cofins), a Contribuição Social Sobre o Lucro Líquido (CSLL), a Contribuição Provisória sobre Movimentações Financeiras (CPMF), existente de 1997 a 2007 (Marques e Mendes, 2004).

É importante destacar que ao se instituir o valor do salário mínimo tanto para o piso do benefício previdenciário como para o BPC, além da cobertura dos trabalhadores rurais, como segurados especiais, garantiu-se a inclusão de milhões de brasileiros pobres como beneficiários da PS de forma universal e redistributiva (Boschetti, 2003), o que melhorou decisivamente a qualidade de vida de milhões de brasileiros.

Atacar as conquistas dos trabalhadores e o Estado provedor foi uma grande estratégia do capital nos anos de 1980-90. Behring (2008) destaca que as mudanças no direcionamento das políticas sociais e no papel do Estado somente podem ser compreendidas no contexto das transformações do capital em nível mundial e operadas a partir dos anos 1970, quando se busca retomar as altas taxas de acumulação do padrão produtivo e empresarial a partir das determinações do modelo de gestão da produção e do trabalho de conformidade com o toyotismo, caracterizado pela produção flexível, que demandou também a reorientação do papel do Estado de cunho neoliberal.

A crise econômica dos anos 1970 deu amplo espaço para que as ideias pautadas na liberdade completa do capital ganhassem terreno com um discurso "imbuído de aura de imparcialidade científica" (Klein, 2008, p. 73) frente à busca de retomada das taxas de acumulação do capital. Assim, o mercado impôs verdadeiros choques econômicos ao Estado para a suposta recuperação da crise, que, desde então, ficou dependente do cumprimento do ajuste fiscal e das medidas de liberalização da economia (Klein, 2008). 
No Brasil, a partir dos anos 1990, os governos adotaram as medidas neoliberais caracterizadas pela abertura das fronteiras econômicas; eliminação das regulações e dos subsídios às empresas locais, privatização, fim das taxações sobre os produtos estrangeiros, flexibilização das relações de trabalho. Além disso, reduziu-se o investimento público na área social e foi delegada à sociedade civil a responsabilidade pela gestão e efetivação de políticas sociais, conforme aponta Laurell (1997), no caso latino-americano.

Nesse contexto, arbitrariamente, decide-se pela destruição dos sistemas de Seguridade Social e de proteção do trabalho, favorecendo a ascensão do capital financeiro (Lourenço, 2015). Os resultados dessa estratégia colocam sérios desafios às classes trabalhadoras, sobretudo nos países em desenvolvimento, como é o caso da América Latina, onde a superexploração do trabalho foi e é mais intensa e os direitos sociais e do trabalho ocorreram apenas tardiamente.

Tal estratégia, além de perpetrar toda uma série de fatos materiais, sociais e políticos para que a segurança social seja viabilizada pelo mercado, e não pelo Estado, precarizou os serviços sociais a tal ponto que a dependência deles significa risco, insegurança e medo. Disso decorre que trabalhadores mais bem aquinhoados pagam, em conjunto com as empresas onde trabalham, planos de seguro-saúde e convênios médicos, escolas particulares e, agora, investem em previdência privada.

Há uma inversão do desejo. Lutas sociais que outrora alargaram o papel do Estado, promovendo a redistribuição da renda socialmente produzida, sobretudo nos dois últimos decênios, retroagem, e alguns setores do sindicalismo entregam-se aos fascínios da promessa dos fundos de investimento, aceitando trocar PS pública pela previdência privada. A práxis política é reflexo da estrutura do mercado de trabalho, hoje marcado por insuportáveis níveis de desemprego. Então, muitas forças e circunstâncias conduzem para a aquisição do "bem-estar" via mercado, enquanto o Estado volta-se ao papel de principal instrumento da acumulação do capital (Marques e Mendes, 2004).

O Estado promove as contrarreformas da PS para torná-la superavitária, destinando o excedente aos bancos e serviços da dívida. Exemplo disso é a criação da Desvinculação das Receitas da União (DRU), sendo que, em 2016, o Congresso Nacional aprovou uma Emenda Constitucional que permitiu a prorrogação da sua existência até 2023 e aumentou a retirada dos recursos da 
Seguridade Social na medida em que a DRU passou de $20 \%$ para $30 \%$ do orçamento da União. ${ }^{1}$ É no mínimo paradoxal fazer um discurso de crise financeira da PS e, ao mesmo tempo, retirar 30\% dos seus recursos e transferi-los para outros fins, e não àqueles para os quais foram arrecadados!

Este ensaio teórico se constrói sobre esse paradoxo, por meio de pesquisa bibliográfica e documental e de amplas discussões realizadas durante o desenvolvimento de uma disciplina sobre a Seguridade Social no Programa de Pós-Graduação em Saúde Coletiva da Universidade Federal de São Paulo, ministrada pelos autores, consecutivamente, nos anos 2015 e 2016.

\section{A contrarreforma² da Previdência Social nos governos de FHC, Lula e Dilma}

A eleição e reeleição de FHC para presidente da República (1995 a 1998 e de 1999 a 2002), por ter sido considerado o "pai" do Plano Real para a estabilização da economia, desenhou um contexto social e político que, segundo Duarte (2003), eliminou os possíveis constrangimentos sociais para impedir o governo de avançar com as suas propostas de contrarreformas.

Na América Latina, as políticas sociais eram de caráter incipiente e, até hoje, segundo Marques (2003), o Brasil é o único, na região, a conseguir a unificação e a uniformização dos benefícios previdenciários. Apesar disso, esses países foram acusados de terem originado a crise do capital e seu aprofundamento, daí a necessidade de amplas "reformas".

1. A prorrogação da Desvinculação das Receitas da União (DRU) para até 2023, estendendo para estados e municípios o aumento de $20 \%$ para $30 \%$ do percentual a ser desvinculado/realocado das "receitas oriundas das contribuições sociais e econômicas, as taxas arrecadadas, os fundos constitucionais (FCO, FNE e FNO) e as compensações financeiras pela utilização de recursos hídricos para geração de energia elétrica e de outros recursos minerais" (Brasil, 2015a), que deveriam ir para o financiamento da Seguridade Social é fruto da Proposta de Emenda à Constituição (PEC) n. 87/2015, de autoria da presidenta Dilma Rousseff, aprovada sob o "governo" de Michel Temer. É mais uma estratégia de superávit primário, justificado sob o objetivo de pagamento de juros da dívida pública, a qual deveria ser auditada.

2. Utiliza-se o termo contrarreforma da PS no sentido já desenvolvido por Behring (2008), uma vez que essas "reformas", que vêm sendo implementadas a partir do neoliberalismo, representam um conjunto de medidas que atendem estritamente ao objetivo de cortar gastos com o social e, portanto, de cortar direitos sociais, como é a proposta atual (PEC n. 257), que significará o verdadeiro desmonte da PS, se aprovada. 
Sob o argumento de baixo crescimento econômico, desemprego, queda na arrecadação e desequilíbrio nas contas públicas constrói-se a crise fiscal do Estado. Entende-se, aqui, que essa, antes de ser uma característica da realidade unicamente nacional, é na verdade uma requisição do capitalismo mundial globalizado e financeirizado, que precisava (e precisa) aumentar as taxas de acumulação, em especial a partir da crise econômica de 2008 (Lacaz, 2016; Lourenço, 2016).

A CF de 1988 é indicada no governo de FHC, em 1995, especialmente no Plano Diretor da Reforma do Aparelho do Estado (PDRAE) como "um novo populismo patrimonialista [que] surgia no país" (Brasil, 1995, p. 20), uma verdadeira amarra da administração pública, impedindo a sua governança e aumentando o custo da máquina administrativa, daí a necessidade da Reforma do Aparelho de Estado (Brasil, 1995).

Quando FHC assume a presidência em 1995, a contrarreforma da PS não era alheia à política já adotada com o Plano Real e, portanto, é defendida como estratégia para o controle da dívida pública, possível estabilização econômica e confiança dos investidores estrangeiros. Já no PDRAE, Bresser-Pereira, então titular do Ministério da Administração e Reforma do Estado (Brasil, 1995), havia criticado ferozmente os funcionários públicos, porque teriam muitos privilégios, como a estabilidade no emprego, o que, para ele, deveria acabar, pois o caráter protecionista inibia o espírito empreendedor, sendo o Regime Jurídico Único (RJU) apontado como uma dificuldade da administração pública e da "inovadora" gestão empresarial que ele propunha para os serviços públicos, tendo em vista que a estabilidade provocava a não valorização do trabalho. Daí, como medidas a serem adotadas e como um dos princípios para a contrarreforma da PS dos funcionários públicos (regimes próprios), advogava a demissão por insuficiência de desempenho, pois "não há dúvida que sem ela será muito difícil, senão impossível, levar o funcionário comum a valorizar o seu emprego" (Brasil, 1995, p. 40).

Assim é que, em 1995, a PEC n. 33, encaminhada ao Congresso Nacional, propôs alterar a aposentadoria e benefícios dos segurados da Previdência Social pública e gerida pelo INSS, o que afetou os que são cobertos pelo RGPS e RPPS, respectivamente, com exceção dos militares das Forças Armadas. A tramitação 
da PEC n. 33 levou mais de três anos até a sua aprovação, a qual se deu com a Emenda Constitucional n. 20, aprovada em 15 de dezembro de 1998 (Marques e Mendes, 2004; Silva, 2004), provocando alterações, sobretudo, em relação ao aumento do tempo de contribuição e retardamento do acesso à aposentadoria tanto para o RGPS quanto para o RPPS. Além disso, retirou a constitucionalidade existente do cálculo para o valor dos benefícios, permitindo a criação de uma lei complementar, em 1999, que instituiu o Fator Previdenciário (FP), o qual impôs uma espécie de multa a quem quisesse aposentar-se sem ter atingido os requisitos instituídos. A criação do FP foi uma resposta ao aumento da expectativa de vida, após sessenta anos, da população brasileira, pois prolongou o tempo de contribuição e inibiu a aposentadoria precoce ao instituir uma forma de cálculo para o valor da aposentadoria condicionada às informações do Instituto Brasileiro de Geografia e Estatística quanto à sobrevida do trabalhador, vinculado a uma taxa variável e relacionada à idade e ao tempo de contribuição (Salvador, 2005).

Marques e Mendes (2004) destacam que como não foi aprovada a proposta da aposentadoria por idade, estipulada em 65 anos (homem) e 60 anos (mulher) - sendo que os trabalhadores rurais têm o direito de se aposentar cinco anos antes da idade então estipulada - , o governo de FHC criou o Fator Previdenciário (FP), saiu vitorioso no aumento do tempo de contribuição e na diminuição do tempo do gozo do benefício, já que o seu valor para aquele que se aposenta mais cedo fica bastante reduzido, o que estimularia o contribuinte a permanecer mais tempo no mercado de trabalho.

Para alcançar níveis elevados de superávit primário foi necessário aumentar o quantitativo de tempo de contribuição, postergando para um período longínquo o acesso à aposentadoria.

As aposentadorias especiais foram praticamente extintas, permanecendo esse direito apenas para professores (exceto os universitários) e trabalhadores em atividades insalubres. Também foi abolida a pensão integral por morte e feito um grande esforço para aprovar a contribuição previdenciária dos aposentados, o que foi inviabilizado pelo Supremo Tribunal Federal, inclusive vetando a ação já praticada por alguns estados e municípios (Silva, 2004). Com isso ressalta-se o caráter securitário da PS desvinculando-a do conceito de Seguridade Social, garantido no texto constitucional. 
É bom lembrar que, no Brasil, grande parte dos trabalhadores não tem como comprovar tempo de contribuição porque estão imersos em trabalhos precários, subcontratados, com baixos salários e expostos a condições de vida insalubres e a condições de trabalhos que causam acidentes, doenças e invalidez (Lacaz, 2016). Assim, exigir tempo maior de contribuição é impor um sacrifício demasiado a quem já tem uma condição de vida e trabalho sacrificada.

No governo de FHC também foi criado o Fundo Social de Emergência (FSE), em 1995, constituído de 20\% das contribuições previstas para o financiamento da Seguridade Social para serem usados livremente pelo governo, inclusive para pagamento de juros da dívida (Marques e Mendes, 2004). O FSE deveria ter vigência de apenas dois anos, mas foi sucessivamente prorrogado, sendo renomeado em 1997 para Fundo de Estabilização Fiscal "e, finalmente, para expressar o seu verdadeiro caráter, Desvinculação das Receitas da União — DRU — em 2000" (Marques e Mendes, 2004, p. 6).

A contrarreforma da Previdência de FHC trouxe regras comuns aos dois regimes (RGPS e RPPS), estipulando um teto para as aposentadorias. Contudo, não foi aprovado o teto das aposentadorias dos funcionários públicos federais, em decorrência de amplas manifestações desse segmento contrário às medidas, e não havia como obrigar a compra da previdência complementar, fato que será modificado na contrarreforma do primeiro governo de Dilma Rousseff.

Silva (2004) discute que no governo de FHC, para justificar a contrarreforma da PS, utilizou-se do discurso da desigualdade de valores dos benefícios entre os que têm acesso ao RGPS e os que têm acesso aos benefícios e aposentadorias dos RPPS, os quais teriam direito à aposentadoria integral. Assim, a existência de dois regimes (Geral e Próprio) seria fonte de grande injustiça, uma vez que os funcionários públicos teriam direito à aposentadoria integral e o acesso a valores mais altos, o que traria diferenças na totalidade das transferências efetuadas pela União para os RPPS. Essa tese também foi difundida pela equipe do ex-presidente Luiz Inácio Lula da Silva no momento da contrarreforma de 2003 e, novamente, é utilizada na proposta do "governo" Temer.

A eleição de Luiz Inácio Lula da Silva, no final de 2002, foi uma grande esperança para as classes trabalhadoras, que se sentiam representadas no novo governo num país sempre comandado por uma classe dominante dependente, típica do capitalismo periférico. 
Contudo, como nos governos FHC, a agenda do Banco Mundial e do Fundo Monetário Internacional continuou a ser implementada e, no que diz respeito à PS, foi concretizada a contrarreforma que afetaria os trabalhadores dos serviços públicos, vinculados ao RPPS, a qual foi iniciada, mas não aprovada no governo de FHC. Segundo Marques e Mendes (2004) na contrarreforma da PS dos funcionários públicos, em 1997, FHC não teve êxito quanto à supressão da integralidade da aposentadoria com valor igual ao servidor da ativa, bem como do direito à paridade de reajuste, bem como a exigência de contribuição dos aposentados. Visando aprovar esses itens, o governo Lula encaminhou ao Congresso Nacional, no início de 2003, a proposta de contrarreforma, que foi aprovada em 7 de agosto desse ano pela Câmara de Deputados e, em 19 de dezembro de 2003, pelo Senado, de conformidade com a PEC n. 41 (Marques e Mendes, 2004).

A contrarreforma da PS no governo Lula atingiu especialmente trabalhadores públicos e foi justificada como uma medida de justiça social, pois eram atribuídos aos servidores públicos possíveis privilégios que os trabalhadores do setor privado não têm, como o discurso já usado por FHC. O governo Lula, além disso, preconizava o fortalecimento da previdência privada sob o pretexto de renda complementar.

A PEC n. 40, aprovada anteriormente em 30 de abril de 2003, "preparou o terreno", fixando o teto de remuneração e de proventos para os funcionários públicos e agentes políticos, extinguindo as regras de transição para a aposentadoria voluntária e estabelecendo critérios de contribuição para o aposentado, "A cobrança dos inativos servidores foi derrotada em três oportunidades durante $\mathrm{o}$ governo FHC e contou sempre com o voto contrário do Partido dos Trabalhadores. Antes dele, somente o último governo militar ousou cobrar de aposentados, no caso então do INPS" (Marques e Mendes, 2004, p. 11).

Sob os governos petistas, ao se estipular um teto para as aposentadorias (Regime Geral e Próprio) visou-se estimular a previdência privada, de caráter individual (aberta), além de estimular segmentos de trabalhadores de empresas estatais e de sindicatos, bem como centrais sindicais, a gerirem o sistema de previdência privado, comumente denominado fundos de pensão. Esse tipo de previdência (privada), como refere Granemann (2006), não é uma conquista 
dos trabalhadores, que nas lutas sociais organizam-se e reivindicam direitos ao acesso de parte da riqueza socialmente produzida, mas é uma veleidade do capital que, na ânsia por novas áreas de exploração e de acumulação, passa a ocupar espaços que até então estavam reservados à responsabilidade do Estado, como é o caso da PS. Nesse processo, além de retrair o papel do Estado frente às políticas sociais, a pressão do capital sobre os governos ainda promove a transferência do fundo público, constituído de contribuições sociais recolhidas para a garantia de direitos, o qual é desviado para o pagamento de juros da dívida pública, beneficiando quem detém os títulos da dívida, no caso o capital financeiro. "Previdência complementar é bandeira do capital, não está organizada por solidariedade, mas por capitalização!” (Granemann, 2015). Além do mais, a previdência privada é organizada a partir da lógica de fundos de investimentos, propiciando o monopólio no setor e transformando trabalhadores em investidores que, tendencialmente, passam a defender a necessidade de ajuste fiscal, demissões, revisão de direitos trabalhistas etc. (Granemann, 2015).

Obrigar funcionários públicos a aderirem à previdência privada - dita complementar, adjetivo este usado para esvaziar o sentido mercadológico dado ao direito - é um excelente negócio para o sistema bancário, tendo em vista que, no caso dos trabalhadores públicos, considerando sua estabilidade, existiriam maiores garantias de pagamento das mensalidades.

Em síntese, o que se pretende frisar é que a contrarreforma da PS estatal (Regime Geral e Próprio) praticada pelo governo Lula, já no início do seu primeiro mandato, atende aos interesses do capital financeiro na busca de clientes para os fundos de investimentos. Sob a denominação de fundos de previdência privada aberta e fechada, cria-se no imaginário social a possibilidade de maiores ganhos e segurança, que o termo "fundos de investimentos" não subentende (Granemann, 2015). Ou seja, a noção de risco que acompanha a operação passa para o campo aparentemente "neutro" da previdência privada.

Verifica-se que o governo Lula deu continuidade à política de restrição do papel do Estado na efetivação dos direitos sociais, "inclusive elevou voluntariamente o superávit fiscal primário para 4,25\%" (Marques e Mendes, 2004, p. 12).

Além disso, as alegadas dificuldades da PS quanto à falta de financiamento são decorrência da não contribuição do Estado, enquanto empregador, no caso do 
RPPS; das sonegações e da realocação dos recursos da Seguridade Social para outras finalidades (tal como é o caso da DRU), não sendo objeto de discussão e debate com a sociedade. Importa observar que quando FHC criou o FSE, depois denominado DRU, o Partido dos Trabalhadores (PT) fez forte oposição. Mas o governo encaminhou a proposta de sua manutenção até 2007, alegando que essa seria uma cautela frente às incertezas do cenário internacional. Assim, "chama de cautela o expediente da desvinculação de recursos da seguridade para engrossar o superávit primário exigido pelo FMI para pagamento da dívida pública, interna e externa" (Marques e Mendes 2004, p. 6).

Cabe observar que parte do sindicalismo brasileiro vinculado à Central Única dos Trabalhadores (CUT), ligada ao PT, manifestou-se favorável ao processo de mercantilização do sistema previdenciário, seguindo a orientação do governo Lula de que os fundos de pensão gerariam poupança interna. $\mathrm{O}$ governo Lula, para Marques e Mendes (2004, p. 12), "está convencido de que a criação de fundos de pensão, para os servidores, formará poupança interna expressiva, o que financiará o desenvolvimento do país".

Nessa linha, $\mathrm{o} 11^{\circ}$ Congresso da CUT (XI Concut), realizado durante a primeira gestão de Dilma Rousseff, enfatizou a importância dos investimentos nos fundos de pensão. E, sob anuência de Dilma, foi sancionada a Lei n. 12.618/12 (Brasil, 2012), que trata da previdência complementar (privada) do funcionalismo público e cria três fundos de pensão: Entidades Fechadas, denominadas Fundação de Previdência Complementar do Servidor Público Federal do Poder Executivo (Funpresp-Exe); Fundação de Previdência Complementar do Servidor Público Federal do Poder Legislativo (Funpresp-Leg) e Fundação de Previdência Complementar do Servidor Público Federal do Poder Judiciário (Funpresp-Jud) (Brasil, 2012). Com as Funpresp, que nada mais são do que fundos de pensão do funcionalismo público federal, todo trabalhador que entra no serviço público, após 2012, terá os benefícios do Regime Próprio do Servidor público federal, limitados ao teto do INSS, o que é um convite para sua adesão à previdência complementar. Nesse caso, o trabalhador contribui para RPPS até o teto, no percentual de $11 \%$ e, acima disso, pode contribuir com o percentual que desejar para a Funpresp. Ademais, o Estado também financia o fundo (privado) com até $8,5 \%$ da parcela da remuneração que exceda o teto do INSS (Brasil, 2012; Granemann, 2015). 
A contrarreforma da PS no governo Dilma afetou profundamente a PS, promovendo desonerações às empresas e amplas mudanças para o acesso às pensões por morte, auxílio-doença, reclusão e defeso e, ainda, abono salarial e seguro-desemprego, com o objetivo de minimizar os valores pagos mensalmente e reduzir o tempo de acesso a esses benefícios, como são exemplo as Medidas Provisórias n. 664 e 665 (Salvador, 2015). Além disso, permite que o INSS faça convênios para a realização de perícias médicas, terceirizando as perícias, assunto caro a Saúde do Trabalhador (ST), devido ao histórico de não reconhecimento dos agravos à saúde relacionados ao trabalho. Salvador (2015) destaca que as Medidas Provisórias n. 664 e 665, transformadas em leis, promoveram amplas dificuldades para o acesso aos direitos previdenciários e ao seguro-desemprego, seguindo a tendência neoliberal de enxugar os gastos sociais e promover o desvio de recursos para a esfera financeira, bem como estimular a previdência privada.

Em novembro de 2015, a Lei n. 13.183 (Brasil, 2015b), ainda no segundo governo de Dilma Rousseff, permite uma alternativa ao Fator Previdenciário, instituído por FHC, quando o trabalhador atingir certa pontuação mediante a somatória de idade e tempo de contribuição, sendo 85 pontos para a mulher e 95 para o homem. Essa lei também previa o direito à desaposentação, com o recálculo do benefício a partir de sessenta novas contribuições, o que não seria permitido nas aposentadorias por invalidez e especial. Mas a desaposentação foi vetada por Dilma Rousseff. Ademais, a Lei n. 13.183 (Brasil, 2015b) impõe aos funcionários que ingressarem no serviço público federal o vínculo automático ao regime de previdência complementar nela previsto.

Granemann (2015) explica que seria inconstitucional obrigar um trabalhador a aderir à previdência privada. Assim, a Lei n. 13.183 (Brasil, 2015b) trata do vago mas autoritário conceito de vínculo "automático" para todos que ingressarem como servidores públicos federais, sendo garantido o direito de desligamento posterior. É mais uma afronta à CF de 1988, que trata a previdência complementar como facultativa, defende Granemann (2015).

Nas contrarreformas anteriores, a conjuntura política tanto no governo de FHC quanto de Lula, não permitiu instituir a previdência privada para os funcionários públicos federais. Deve-se salientar que isso se tornou realidade numa nova conjuntura política, sob o PT, a partir da Lei n. 12.618/12 (Brasil, 2012) por meio da Funpresp. 
Granemann (2015) esclarece ainda que a previdência privada está sujeita aos riscos do mercado, e no caso de falência, o trabalhador não contará com a segurança do Estado para fazer valer seus direitos.

As mazelas da previdência privada já eram apontadas por Tavares (2003, p. 48): "Sistema de capitalização, seja qual for a forma (aberta ou fechada) não tem poder distributivo, pois seu modelo é individualizado. Há uma brutal transferência da poupança pública para a poupança privada e nenhum retorno para os empregados".

\section{A PS por um fio: a contrarreforma sob Temer}

A contrarreforma em curso visa atacar os pilares dos princípios beveridgeanos. Trata-se de um processo político e ideológico que limita o papel do Estado na área social, criando as condições e a estrutura necessárias para que o capital explore financeiramente as políticas sociais, em especial a da PS. É um processo de mercantilização do direito, que no Brasil ganhou coro a partir dos anos 1990, quando os governos passam a negar a Constituição recém-promulgada e situam a cidadania essencialmente atrelada ao consumo e ao individualismo.

Neste momento, no Brasil, ocorre uma forte ofensiva do capital financeiro para destruir os direitos sociais tanto trabalhistas como previdenciários. $\mathrm{O}$ Executivo federal por meio da PEC n. 287 (Brasil, 2016a), um complemento ao chamado "pacote fiscal" proposto na PEC n. 55 e já aprovado pelo Congresso Nacional (Brasil, 2016b), volta à carga sob a alegação, dentre outros argumentos, de que o sistema previdenciário é deficitário (Fagnani, 2016).

Ressalta-se a extinção do Ministério da Previdência Social (MPS), "substituído" pela Secretaria Nacional da Previdência vinculada ao Ministério da Fazenda. O fato de o MPS ter sido extinto e incorporado ao Ministério da Fazenda - algo inédito no mundo - demonstra a estratégia do capital financeiro, ou seja, colocar os direitos previdenciários sob a tutela do mercado, transformando-os em mercadorias (Lacaz, 2016).

Pelo que aponta a proposta de contrarreforma em debate, o tempo de contribuição para aposentadoria integral será de 49 anos e a idade será de 65 anos, 
tanto para homens como para mulheres. Desta forma, as mulheres serão as mais prejudicadas porque eram protegidas na $\mathrm{CF}$ de 1988. A diferença de idade para aposentadoria hoje existente, de cinco anos entre homens e mulheres (65 e 60, respectivamente), leva em conta a maior carga de trabalho das mulheres pela jornada dupla em casa e no trabalho.

A tese divulgada pelo governo e defendida por economistas e mídia conservadores é que estatisticamente as mulheres vivem mais em relação aos homens e, portanto, acumulam aposentadoria com a pensão, já que 1/4 das mulheres com idades entre 60 e 69 anos são viúvas (Brasil, 2015c). Contudo, não se fala que as mulheres acumulam papéis conjugando trabalho fora de casa com os afazeres domésticos e cuidados de filhos e pessoas dependentes. Além disso, os dados oficiais sobre mercado de trabalho destacam que as mulheres exercem as ocupações de baixa remuneração, sendo a esmagadora maioria dentre os trabalhadores domésticos com ou sem carteira de trabalho assinada (Brasil, 2015c). A desigualdade laboral persiste também entre as ocupações exercidas nos serviços públicos, ainda que sob o regime estatutário (Brasil, 2015c).

Uma restrição de maior intensidade é o que propõe o "governo" Temer, ao desvincular o reajuste do BPC do salário mínimo. Aqui, retornam as práticas da ditadura militar, quando os benefícios eram corrigidos abaixo do índice de inflação, o que foi revisto na CF de 1988.

Observa-se, nos limites deste texto, que as medidas em curso, sob a justificativa de aplacar o chamado déficit, não consideram o total de recursos arrecadados com as contribuições sociais, como aponta a Associação Nacional dos Auditores Fiscais da Receita Federal (Anfip). A CF n. 1988 prevê que sejam consideradas todas as fontes de receita da Seguridade Social, o que resultaria em superávit, como ocorreu em 2010 (R \$ 56,7 bilhões); em 2012 (R \$ 78,1 bilhões); em 2014 (R \$ 56,4 bilhões); em 2015 (R \$ 11 bilhões), mesmo com o desvio de recursos para a DRU (R 61 bilhões em 2015) e com a isenção fiscal dos últimos cinco anos da ordem de R $\$ 142$ bilhões somente em 2015 (Stevanim, 2016).

Ocorre que, como assinala Denise Gentil, o cálculo do orçamento deve contabilizar outras fontes, como a Cofins. Segundo Gentil, em entrevista, "o governo e as instituições financeiras rasgam a Constituição e isolam a previdência como se tivesse uma única fonte de receitas" (Stevanim, 2016, p. 26). 


\section{Considerações finais}

A Seguridade Social é uma importante conquista inscrita na CF de 1988, sendo constituída pela PS, pela Assistência Social (Suas) e pela Saúde (SUS). Todavia, sempre esteve sob ataque das forças políticas conservadoras e nunca se viabilizou de fato como política integrada de proteção social (Lacaz, 2016).

Neste momento, no Brasil, tem ocorrido uma forte ofensiva do capital para destruir os direitos sociais, trabalhistas e previdenciários, cuja argumentação para colocar em prática a contrarreforma da PS está calcada no mito do seu déficit.

Conforme elencado, os dados indicam que não há déficit da PS, pois se fosse seguido o que prevê a CF de 1988 em seu artigo 194, o orçamento da Seguridade deveria contar com 1/3 de contribuição da União, além de 1/3 de trabalhadores e de empresas. Ademais, na CF de 1988 foram criadas a Cofins e a CSLL.

Entretanto, desde o final do governo Sarney (1985-89), deixou-se de cumprir essa determinação, quando o governo apropriou-se das novas fontes de financiamento, contabilizando somente a contribuição de empresários e trabalhadores para financiar a PS, não a considerando como componente da Seguridade Social. Tal situação inconstitucional iniciada em 1989 continuou sob os governos posteriores de FHC, Lula e Dilma, e o dito "rombo" financeiro é resultado dessa estratégia.

Do ponto de vista do financiamento da Seguridade, a elevação da DRU de $20 \%$ para $30 \%$ do orçamento da União retira recursos das áreas sociais para aplicá-los no pagamento de juros da dívida pública, cabendo a indagação de Fagnani (2016): por que não reduzir os gastos com juros (R $\$ 500$ bilhões em 2014 ou 9\% do PIB); tributar as grandes riquezas e as heranças; rever incentivos fiscais ( $\$ 300$ bilhões em 2016 ou 25\% das receitas federais); combater a sonegação fiscal (14\% do PIB)?

Ao se questionar a quem interessa propagar o mito do déficit na PS, Denise Gentil, em entrevista (Stevanim, 2016) aponta para os fundos de previdência privada que são ligados aos grandes bancos. Ao ser alardeado que a PS está falida, as pessoas, por insegurança, optam pela previdência complementar, o que passou a ocorrer com a contrarreforma promovida pelo governo Dilma em 2013, no caso dos servidores públicos federais, que passaram a aposentar-se com o salário igual ao teto do INSS, como já foi assinalado. Ademais, usar o 
montante das contribuições sociais para pagar juros da dívida externa brasileira significa não financiar a PS, a Saúde e a Assistência Social (Stevanim, 2016).

Consideram-se também os apontamentos de Rosa Marques, no que se refere ao impacto do envelhecimento da população brasileira nas contas da PS, como justificativa para adoção arbitrária das medidas "reformistas" em curso. Marques (2017) concorda que o Brasil não tem uma população largamente jovem, mas discorda que se trata de um país envelhecido, ou que a alteração da pirâmide demográfica seja um fator negativo. Ao contrário, a pesquisadora endossa a necessidade de gerar um mix de fontes de recursos que possa financiar as aposentadorias frente à nova configuração demográfica.

Outro aspecto que sustenta a proposta da contrarreforma atual é a falácia de ausência da idade mínima para aposentadoria: tal inverdade data da contrarreforma ocorrida no governo FHC, quando da Emenda Constitucional n. 20/1998. Com ela foram instituídas duas formas de aposentadoria: por "idade" e por "tempo de contribuição". A primeira é devida a homens com 65 anos de idade e mulheres de sessenta anos, com mais de quinze anos de contribuição (trabalhador urbano). Os trabalhadores rurais podem aposentar-se aos sessenta anos no caso dos homens e 55 anos no caso de mulheres. Há, sim, portanto, aposentadoria por idade, a qual corresponde a mais de $70 \%$ das que são hoje concedidas (Stevanim, 2017; Anasps, 2016³).

Desde 1998, no Brasil, exige-se idade mínima igual ou superior à dos países mais desenvolvidos, cujos PIB per capita e expectativas de vida são bem maiores. Deve-se salientar que, em 1988, a idade de 65 anos não era exigida na Bélgica, Alemanha, Canadá, Espanha, França e Portugal, que exigiam sessenta anos, ou Estados Unidos (62 anos), sendo igual à época ao que era exigido na Suécia, Alemanha e Áustria (Fagnani, 2016). Tal realidade demonstra que o Brasil, um dos países mais desiguais do mundo, adotava critérios semelhantes aos menos desiguais, fazendo crer que ao se adotado novo limite de idade, como se pretende, este será provavelmente mais avançado.

3. Mais de 21 milhões de aposentados e pensionistas do INSS - de um total de 31,5 milhões - estão recebendo um salário mínimo ( $\mathrm{R} \$ 724)$, atualmente. O número equivale a 71,6\% dos beneficiários. Em 2005, essa proporção era de 67,8\%, com 16,3 milhões de segurados recebendo o piso nacional. Os dados fazem parte de um levantamento da Associação Nacional dos Servidores da Previdência e da Seguridade Social, sobre o achatamento dos benefícios nos últimos anos (Anasps, 2016). 
Outro aspecto a ser considerado na contrarreforma em curso diz respeito à idade mínima de 65 anos e 49 anos de contribuição, tanto para homens como para mulheres. Tal proposição desconsidera as grandes diferenças de inserção da mulher no mercado de trabalho, bem como as diferenças de esperança de vida nos vários estados do país, na medida em que, por exemplo, segundo o IBGE, ao nascer em Alagoas e esperança de viver é de 66 anos, ao passo que em Santa Catarina a expectativa de vida de uma mulher pode ser de 81,8 anos (Stevanim, 2016). O que irá acontecer é que, sendo fixada uma idade mínima num país continental e com tantas diferenças como o Brasil, condena-se uma parcela a não conseguir aposentar-se (Idem).

Trata-se de negar e de anular conquistas arduamente obtidas, agora sob a égide da austeridade, sinônimo de supressão de direitos sindicais, trabalhistas e sociais, ao mesmo tempo em que são congelados, com o "ajuste fiscal", recursos vinculados à educação, à saúde, o que se acompanha de forte ataque à PS (Lacaz, 2016).

É importante destacar ainda que, paralelamente à contrarreforma da PS está ocorrendo a destruição da Consolidação das Leis do Trabalho (CLT) e da Justiça do Trabalho, que já vinham sendo impactadas pela flexibilização do trabalho e reestruturação produtiva. Este "governo" está impondo a terceirização total do trabalho, a prevalência do negociado sobre o legislado e as maiores facilidades das empresas para demitirem os funcionários. Como se sabe, a terceirização significa maior insegurança do trabalho e da vida, com sérias incidências para a saúde dos trabalhadores (Lourenço, 2016; Coutinho, 2015; Navarro e Lourenço, 2017), além do fato de obstaculizar o próprio financiamento da PS.

Entende-se que o ataque às conquistas duramente obtidas pelo movimento sindical ao longo de sua história, previstos em mais esta contrarreforma, exige um amplo processo de mobilização social que una as entidades sindicais e organizações progressistas da sociedade civil num Programa de Consenso de Defesa da Seguridade Social e do Trabalho, caminhando no sentido de realmente torná-la uma realidade, algo que foi descurado pelas lutas dos movimentos sociais no pós-CF/1988.

Recebido em 11/4/2017 - Aprovado em 14/6/2017 


\section{Referências bibliográficas}

ANASPS. Disponível em: $<$ https:/www.anasps.org.br/?s=70\%25+ganham $+1+$ salario+ minimo>. Acesso em: 3 jan. 2016.

BEHRING, E. R. Brasil em contra-reforma: desestruturação do Estado e perda de direitos. São Paulo: Cortez, 2008.

BOSCHETTI. Ivanete. Implicações da reforma da Previdência na Seguridade Social brasileira. Psicologia \& Sociedade, Belo Horizonte, v. 15, n. 1, jan.-jun. 2003. p. 57-96.

BRAGA, Léa; CABRAL, Maria do Socorro Reis. Serviço Social na Previdência. São Paulo: Cortez, 2008.

BRASIL. PEC n. 287. 2016a. Disponível em: <http://www.previdencia.gov.br/wpcontent/uploads/2016/12/PEC-287-2016.pdf>. Acesso em: 3 jan. 2016.

PEC n. 55, PEC do Teto dos Gastos Públicos. 2016b. Disponível em: <http:// www25.senado.leg.br/web/atividade/materias/-/materia/127337>. Acesso em: 3 jan. 2016.

. Proposta renova DRU até 2023 e amplia desvinculação para 30\% da receita. 2015a. Disponível em: <http://www2.camara.leg.br/camaranoticias/noticias/ ADMINISTRACAO-PUBLICA/491966-PROPOSTA-RENOVA-DRU-ATE-2023-EAMPLIA-DESVINCULACAO-PARA-30-DA-RECEITA.html>. Acesso em: 15 jan. 2017.

. Lei n. 13.183, de 4 de novembro de 2015. Presidência da República: Casa Civil, 2015b. Disponível em: <http://www.planalto.gov.br/ccivil_03/Ato2015-2018/2015/ Lei/L13183.htm>. Acesso em: 11 mar. 2016.

. Informe da Previdência Social. A mulher e a Previdência Social. Nota técnica. Resultado do RGPS, v. 27, n. 2, jan. 2015c. Disponível em: <http://www.previdencia. gov.br/wpcontent/uploads/2016/06/informe_2015.02.pdf >. Acesso em: 15 dez. 2015.

. Lei n. 12.618, de 30 de abril de 2012. Institui o regime de previdência complementar para os servidores públicos federais titulares de cargo efetivo. Presidência da República: Casa Civil. Disponível em: <http://www.planalto.gov.br/ccivil_03/_ ato2011-2014/2012/lei/112618.htm>. Acesso em: 11 mar. 2016.

. Plano Diretor da Reforma do Aparelho de Estado do Brasil. Presidência da República. Brasília: 1995. Disponível em: <http://www.bresserpereira.org.br/ Documents/MARE/PlanoDiretor/planodiretor.pdf>. Acesso em: 28 dez. 2015. 
BRASIL. Lei Orgânica da Assistência Social no 7.842, de 7 de dezembro de 1993. Disponível em: <http://www3.dataprev.gov.br/sislex/paginas/42/1993/8742.htm>. Acesso em: 20 abr. 2015.

COUTINHO, Grijalbo. Terceirização, máquina de moer gente trabalhadora: inexorável relação entre a nova marchandage e a degradação laboral, as mortes e mutilações no trabalho. São Paulo: LTR, 2015.

DUARTE, Adriana. O processo de reforma da previdência social pública brasileira: um novo padrão de regulação do Estado? Serviço Social \& Sociedade. São Paulo, n. 73, p. 120-141, mar. 2003.

FAGNANI, Eduardo. Previdência social: reformar ou destruir? In: JINKINGS, Ivana; DORIA, Kim; CLETO, Murilo (Orgs.). Por que gritamos golpe? Para entender o impeachment e a crise. São Paulo: Boitempo, 2016. p. 85-92.

GRANEMANN, Sara. Aula proferida como professora convidada na disciplina "Sistema Único de Saúde, Sistema Único de Assistência Social e Previdência Social: Questões e Desafios da Seguridade Social no Brasil", no Programa de Pós-Graduação em Saúde Coletiva da Universidade Federal de São Paulo, Unifesp, out. 2015.

. Para uma interpretação marxista da previdência privada. Tese de Doutorado apresentada no Programa de Pós-Graduação em Serviço Social da Escola de Serviço Social da Universidade Federal do Rio de Janeiro (UFRJ), Rio de Janeiro, 2006.

KLEIN, Naomi. A doutrina do choque: a ascensão do capitalismo de desastre. Rio de Janeiro: Nova Fronteira, 2008.

LACAZ, Francisco Antonio de Castro. Precariedade, intensificação do trabalho e saúde do trabalhador: por uma postura anticapitalista das políticas sociais. In: LOURENÇO, E. Â. S. (Org.). Saúde do/a trabalhador/a e Serviço Social: estudos da relação trabalho e saúde no capitalismo contemporâneo. São Paulo: Papel Social, 2016. p. 85-99.

LAURELL, Asa Cristina. Avançando em direção ao passado: a política social do neoliberalismo. In: . (Org.). Estado e políticas sociais no neoliberalismo. São Paulo: Cortez, 1997. p. 151-178.

LOURENÇO, Edvânia Ângela de Souza (Org.). Saúde do/a trabalhador/a e Serviço Social: estudos da relação trabalho e saúde no capitalismo contemporâneo. São Paulo: Papel Social, 2016. 
LOURENÇO, Edvânia Ângela de Souza. Terceirização: a derruição de direitos e a destruição da saúde dos trabalhadores. Serviço Social \& Sociedade, São Paulo. n. 123, p. 447-475, jul./set. 2015.

MARQUES, Rosa Maria. Envelhecimento da população e Previdência Social: a dinâmica demográfica está diretamente relacionada às políticas para aposentadoria. Revista PréUnivesp, São Paulo, n. 61, dez. 2016-jan. 2017. Disponível em: <http://pre.univesp.br/ previdencia-social\#.WNAXytIrLMw>. Acesso em: 15 mar. 2017.

. Experiências internacionais e a reforma da Previdência. In: et al. $A$ Previdência Social no Brasil. São Paulo: Fundação Perseu Abramo, 2003. p. 17-30.

; MENDES, Áquilas. O governo Lula e a contra-reforma previdenciária. São Paulo em Perspectiva, São Paulo, v. 18, n. 3. p. 3-15, jul.-set. 2004.

NAVARRO, Vera Lúcia; LOURENÇO, Edvânia Ângela de Souza. O avesso do trabalho $I V$ : terceirização: precarização e adoecimento no mundo do trabalho. São Paulo: Expressão Popular, 2017.

SALVADOR, Evilásio. Fundo Público e as Medidas Provisórias ns. 664 e 665: a contrarreforma da Previdência em curso. Maio 2015. Disponível em: <http:// plataformapoliticasocial.com.br/fundo-publico-e-as-medidas-provisorias-664-e-665a-contrarreforma-da-previdencia-em-curso/>. Acesso em: 21 jan. 2016.

. Implicações da reforma da Previdência sobre o mercado de trabalho. Serviço Social \& Sociedade. São Paulo, n. 81, p. 7-39, mar. 2005.

SILVA, Ademir Alves. A reforma da Previdência Social brasileira entre o direito social e o mercado. São Paulo em Perspectiva, São Paulo, v. 18, n. 3, p. 16-32, jul.-set. 2004.

STEVANIM, Luiz Felipe. O mito do rombo. RADIS, n. 167, p. 25-27, ago. 2016. Disponível em: <http://www6.ensp.fiocruz.br/radis/revista-radis/167/reportagens/ entrevista-denise-gentil>. Acesso em: 28 fev. 2017.

. Seguridade social. Sem proteção. RADIS, n. 173, p. 17-23, fev. 2017. Disponível em: <http://www6.ensp.fiocruz.br/radis/revista-radis/173/reportagens/sem-protecao>. Acesso em: 3 mar. 2017.

TAVARES, Laura Soares. Reforma da Previdência: a experiência da América Latina. In: MARQUES, Rosa et al. A Previdência Social no Brasil. São Paulo: Fundação Perseu Abramo, 2003. p. 37-50. 